\title{
Formas crepusculares, dores silenciosas: o teatro simbolista de Roberto Gomes
}

Elen de MEDEIROS ${ }^{1}$

Universidade de São Paulo - USP

"Ily a un tragique quotidien qui est bien plus réel, bien plus profond et bien plus conforme à notre être véritable que le tragique des grandes aventures."

(Maurice Maeterlinck, Le tragique quotidien)

\section{SiLÊNCIO E INAÇÃO - O ANTITEATRO}

O teatro simbolista teve suas primeiras manifestações na França, no final do século XIX, e tem o dramaturgo belga Maurice Maeterlinck como principal expoente dessa estética precursora de um teatro de vanguarda. Com um princípio nãonacionalista, rompeu as fronteiras e se estendeu por parte do mundo ocidental, impulsionando poetas, dramaturgos e encenadores na composição de um teatro estático; ou, ao menos, um teatro que rompesse com a forma dialógica como principal elemento de comunicação dramática. Embora tenha causado uma repercussão significativa nos palcos - especialmente pela mão de encenadores como Lugné-Poe, na França, e Meyerhold, na Rússia $^{2}$-, essa estética acabou sendo parcialmente esquecida, mesmo que ainda hoje seja possível verificar suas influências indiretas. Um teatro que é muito mais marcado pela poesia do que

\footnotetext{
${ }^{1}$ Mestre e doutora em Teoria e História Literária pelo Instituto de Estudos da Linguagem, IEL, da Unicamp, atualmente desenvolve pesquisa de pósdoutorado na Universidade de São Paulo. Especialista no teatro de Nelson Rodrigues, tem se dedicado ao estudo da teoria do drama moderno. É membro-fundador do Grupo de Estudos em Dramaturgia Letra e Ato, vinculado ao Departamento de Artes Cênicas (IA), da Unicamp. E-mail: elendemedeiros@hotmail.com.

2 É preciso considerar, para a história do teatro, as significativas transformações estéticas causadas pelo teatro simbolista. Não apenas no âmbito da composição dramática essa estética proporcionou um novo olhar, mas também para a cena moderna que se constituirá ao longo do século XX. Ver: ROUBINE (2008); PICON-VALLIN (2006).
} 
pela ação, que pretende o silêncio como elemento de representação do sofrimento e que valoriza novas formas de teatralidade na luz e na música: tudo isso contribuiu para que o simbolismo teatral fosse também conhecido como antiteatro.

Em O trágico quotidiano, Maurice Maeterlinck desenha com certa precisão o ideal de seu drama estático: aquele que será capaz de acolher o ser humano passivo e imóvel diante do mistério de sua existência, no que "há de espantoso no simples fato de viver" (1945, p. 121), que substitua as grandes aventuras das tragédias. Pelo silêncio, o autor belga pretende representar a luta do homem com “as forças superiores que o subjugam” (Moler, 2006, p. 170). Pela indefinição da intriga, a ação deixa de ser o eixo da composição dramática; agora, a situação em que as personagens se encontram é o que se destaca: "Não se trata da luta determinada dum ser contra outro, da luta dum desejo contra outro desejo ou do eterno embate entre a paixão e o dever" (MAETERLINCK, 1945, p. 121).

Partindo desses pressupostos do teatro estático idealizado pelo dramaturgo, é possível compreender como eles se processam na composição estética do drama e apontam para um repensar teatral. Peter Szondi (2001) menciona esse paradoxal drame statique proposto por Maeterlinck como um questionador da forma dialógica, já que ela seria, por um lado, insuficiente para a representação; por outro, o que se tem a dizer não justifica o diálogo. Essa inadequação da forma ao seu conteúdo seria um dos fatores que levaria esse drama a uma crise, deflagrada por vários autores proponentes de um novo formato dramático. Assim como outros dramaturgos, Maeterlinck proporcionou novos rumos ao teatro com sua proposta, desencadeando aspectos que compõem o que hoje é chamado de teatro moderno.

O tema do homem entregue ao seu destino, sem salvação e sem resistência, evidencia a ausência de um conflito que seja o responsável pelo desenvolvimento dramático. Nos dramas simbolistas, especialmente nas primeiras peças de Maeterlinck (do

Pitágoras, 500 - vol. 1 - Outubro 2011 
seu "primeiro teatro"), as personagens não têm controle sobre sua vida, são incapazes de controlar sua história e só lhes resta esperar a morte - a própria ou de alguém próximo. O homem torna-se, assim, impotente e inanimado.

Essa dramaturgia que cria abismos entre as falas dos diálogos coloca um problema ao teatro porque, levando a seu nível máximo a sugestão e a alusão, tende para uma estética do inanimado, do inumano: em vez de procurar imitá-lo, o teatro trágico quotidiano afasta o ser vivo do palco para manifestar-se em primeiro lugar no frêmito da vida interior ou as forças obscuras que subjazem a cada existência sob uma aparência tranquila. (PICCON-VALLIN, 2006, p. 10)

Há, nessa inserção da inação humana no palco, um profundo questionamento da forma dramática tradicional, vigente até o início do século XX, uma vez que a forma dialógica se apresenta como incompatível com o seu conteúdo. As personagens estáticas, por sua vez, apresentam a essência desse antiteatro, que manifesta o estado onírico pela força sugestiva da poesia: "Com a ajuda dos gestos e das variações do diálogo, as repetições e os silêncios eram muito mais capazes de provocar a imaginação e ajudar o espectador atingir o estado onírico do que apenas as palavras impressas no papel" (BALAKIAN, 2007, p. 100). Assim, o silêncio é mais significativo do que o diálogo travado entre as personagens, as sugestões do gesto, da luz e da música não são inócuos, mas procuram simbolizar o estado de espírito do homem.

A própria linguagem perde o seu aspecto dialético, destituída de significado preciso, emitida mais pelo hábito do que por uma real necessidade de estabelecer um juízo ou comunicar uma afirmação, adquirindo então valor nitidamente lírico. (FRAGA, 1992, p. 50)

Em seu aspecto estético-formal, há, por meio desse silêncio, um distanciamento entre o sujeito e o objeto pela inserção de um sujeito épico que descreve a situação. Para exemplificar rapidamente essa oposição sujeito-objeto (o que, 
conforme a teoria de Szondi, faz com que a relação intersubjetiva - aspecto caro ao drama tradicional - seja rompida), consideremos Intérieur (1894), de Maeterlinck, texto que evidencia claramente essa separação.

Na peça, uma família, composta por personagens mudas, está no interior de sua casa, em aparente tranquilidade e imobilidade. No jardim, um velho e um estrangeiro esperam o momento de contar à família sobre a morte da filha mais velha, que se afogou em um rio, enquanto uma multidão se aproxima da casa com o corpo da jovem. Há, no texto, uma nítida divisão: as personagens no jardim, que comentam a situação e descrevem o momento e os gestos da família, em oposição às personagens do interior da casa, mudas, passivas, à espera do seu destino desconhecido, sem condição de lutar contra o que lhes espera. $\mathrm{O}$ principal aspecto de ruptura da forma tradicional do drama, aqui, é o fato de a família tornar-se objeto dos comentários e descrições das outras personagens: a aparente tranquilidade deles, os gestos, a morte da jovem, o seu olhar para o vazio, a vida e a morte:

L'ÉTRANGER: Elle nous regarde...

LE VIEILLARD: Non; elle ne sais pas ce qu'elle regarde; ses yeux ne clignent pas. Elle ne peut pas nous voir; nous sommes dans l'ombre des grandes arbres. Mais n'approchez pas davantage... Les deux soeurs de la morte sont aussi dans la chambre. Elle brodent lentement; et le petit enfant s'est endormi. Il est neuf heures à l'horloge qui se trouve dans le coin... Ils ne se doutent de rien et ils ne parlent pas. (MAETERLINCK, 1904, p. 176)

Mesmo nos momentos em que há um aparente diálogo, percebe-se o vazio do que se fala, apenas descritivamente, sem impulsionar nenhum tipo de ação. Um diálogo cuja beleza está além daquilo que é exteriorizado, quando há nas palavras uma certa inutilidade, e um sentido subjacente ao supérfluo do dito: "É preciso que haja outra coisa além do diálogo exteriormente necessário. (...) Ao lado do diálogo indispensável, há quase 
sempre outro diálogo na aparência supérfluo" (MAETERLINCK, 1945, p. 130).

MARIE: L'aînée ne sourit plus, grand-père...

L'ÉTRANGER: Elles quittent les fenêtres...

MARIE: Elles embrassent leur mère...

L'ÉTRANGER: L'ainnée a caressé les boucles de l'enfant qui ne s'éveille pas...

MARIE: Oh! Voici que le père veut qu'on l'embrasse aussi...

L'ÉTRANGER: Maintenent le silence... (MAETERLINCK, 1904, p. 189)

A simples descrição dos gestos da família provoca um esvaziamento de sentido àquelas palavras ditas por Marie e pelo Estrangeiro, mas intensifica o significado e a beleza dos gestos silenciosos e graves que os membros da família realizam no interior da casa, na medida em que aponta para uma espiritualização deles.

2. MARCAS DO SIMBOLISMO NOS DRAMAS DE ROBERTO GOMES

É pouco provável que possamos assegurar a presença de um teatro simbolista no Brasil, simplesmente pelo fato de que não houve um encenador que levasse ao palco as propostas da inação ou do silêncio como elementos soberanos da composição cênica. Por outro lado, os autores que portaram alguma influência dessa estética procuraram não se afastar demasiadamente do público (cf. FRAGA, 1992), enfatizando aspectos que os distanciam da categorização puramente simbolista. No entanto, sabe-se que alguns autores teatrais brasileiros do início do século XX foram influenciados pelas ideias do chamado drama estático de Maeterlinck. Dentre eles, Roberto Gomes se destaca, uma vez que propunha em seus textos a representação silenciosa da dor, do sofrimento humano e a inação das personagens frente à morte, destino certo do homem. 
O teatro de Roberto Gomes, escrito entre 1910 e 1919, é composto de oito peças em português ${ }^{3}$ e uma em francês, Le papillon. Segundo o estudo introdutório de Marta Morais da Costa para o teatro completo, "o teatro de Roberto Gomes está construído sobre o tema exclusivo do amor. É em torno dele que giram as personagens, seus desejos, lutas e, frequentemente, sua derrota" (COSTA, 1983, p. 23). Essa é uma dramaturgia que procura mesclar duas influências muito nítidas: por um lado, o simbolismo de Maeterlinck, com suas sugestões, silêncios, o sofrimento incontornável e o homem sem controle de seu destino; por outro, o "teatro da paixão" francês, com um olhar examinador da sociedade burguesa, apresentando em minúcias sua hipocrisia, egoísmo e ambição. O confronto dessas duas estéticas ameniza tanto a crueza do "teatro da paixão" quanto a subjetividade do simbolismo.

Dentre os oitos textos escritos em português pelo dramaturgo, serão enfocados três neste estudo: $A$ bela tarde, $O$ jardim silencioso e $A$ casa fechada. São peças curtas, de um ato, em que os aspectos simbolistas se sobressaem e possuem semelhanças formais e temáticas. Nelas, há uma evidente influência do teatro estático de Maeterlinck, tanto pela aproximação estética de composição do drama quanto na constituição da narrativa: são personagens em espera, sem participar de uma ação propriamente dita. São textos que se baseiam em um formato crepuscular para expressar o que as palavras não têm poder de revelar. Neles, há sempre um mistério, o não-dito que permeia a cena.

Trata-se de um teatro impregnado de uma decadentista e refinada visão do mundo e dos homens, expressa poeticamente. Há nessas peças uma evidente preocupação com a psicologia em detrimento da peripécia, com a sensação que secundariza a ação, com

\footnotetext{
${ }^{3}$ Seguem os nomes das peças e as respectivas datas da primeira encenação: $A 0$ declinar do dia... (1910), O canto sem palavras (1912), A bela tarde (1915), O sonho de uma noite de luar (1916), O jardim silencioso (1918), Inocência (1921), Berenice (1923) e A casa fechada (1953).
} 
o silêncio que se sobrepõe ao ruído, com a noite e o crepúsculo, mais sugestivos que o dia. (COSTA, 1983, p. 19)

São esses os principais pontos que o teatro simbolista procura acentuar e dos quais o teatro de Roberto Gomes se apropria. Dentre eles, o tom crepuscular impera nos três textos, adiantando outros detalhes simbolistas, seja o tom decadentista que acompanha as personagens, seja a dor impregnada em sua composição expressada pelo silêncio. É na rubrica inicial das peças que se percebe imediatamente o tom sombrio em que as personagens vão aparecer, sempre envolvidas pela penumbra do final do dia ou pelas sombras da noite parcamente iluminada pelo luar.

Em $A$ bela tarde, a rubrica que abre a cena descreve sobriamente o cenário ${ }^{4}$ e sentencia o tom de construção das personagens principais: "Através das árvores, avistam-se ao longe o Rio e a baía, dourada pelos últimos raios do sol agonizante. Grandes nuvens de ouro e sangue serpeiam pelo céu imenso que resplende. São as derradeiras fulgurações, antes da noite silenciosa que vai lentamente cair" (GOMES, 1983, p. 147. Grifo meu). A peça é dividida em dois momentos bastante distintos: em um primeiro momento, estão em cena os pais, a filha Nicota e o primo Juca. Apesar da atmosfera crepuscular, há uma certa preocupação em apresentar um lado frívolo da vida em família; em seguida, ficam em cena apenas Nicota e Juca. Então, sozinhos, eles vão confidenciar suas dores. Em um diálogo melancólico, repleto de sussurros, soluços e suspiros - que representam a dor sofrida muito mais do que as palavras pronunciadas - eles compactuam um mesmo estado de espírito, igualmente agonizante: Nicota sofre sua primeira desilusão amorosa; e Juca, aos

\footnotetext{
${ }^{4}$ Cenário, aliás, muito próximo daquele descrito por Maeterlinck (1904) em Intérieur: "Un vieux jardin planté de saules. Au fond une maison, dont trois fenêtres du rez-de-chaussée sont éclairées. On aperçoit assez distinctement une famille qui fait la veillée sous la lampe" (p. 175). Em $A$ bela tarde: "Um jardim. À esquerda, a casa, adornada com plantas e trepadeiras" (GOMES, 1983, p. 147).
} 
cinquenta anos, acredita sofrer sua última. A epígrafe da peça já prenuncia o que virá: "Foram duas pequenas dores que se encontraram no crepúsculo...”. Primo Juca é um cinquentão bon vivant que foi abandonado pela amante; Nicota é uma jovem apaixonada cujo pretendente noivou com outra. Dois amores distintos, duas dores que se encontram no silêncio do jardim para revelar suas decepções.

Descrição semelhante de ambiente encontramos em $O$ jardim silencioso: "uma lâmpada cuja luz coada ilumina discretamente a sala. (...) Pela porta do fundo, aberta de par em par, avista-se o jardim adormecido, prateado de luar" (Idem, p. 189). Logo na primeira fala, é informado o horário em que se passa a "ação": oito horas da noite. Em cena, Mariana, Pedro e Helena esperam por Noêmia e, pouco a pouco, revelam uma dor silenciosa de que ninguém ousava falar. É aniversário de Noêmia e todos a esperam para jantar. Quando aparece, ela é apenas uma sombra que passa pelo jardim ao fundo da cena; foi trazida pelo primo, baleada, e está gravemente ferida. É revelado, então, o motivo do acidente e causa de tanta dor na família: Noêmia traía o marido com um jovem, que a ameaçava e chantageava. Revelam-se os sofrimentos, as mágoas reprimidas, tudo envolvido pelo silêncio que imperava. É Helena quem desvela: "Vivíamos num jardim silencioso, onde ninguém ousava falar... Oh! Esse mundo de silêncio que todos carregam em sil”' (Idem, p. 201)

A última peça escrita pelo dramaturgo, em 1919, A casa fechada volta a lidar com o mesmo ambiente taciturno que acompanha as outras peças. Apesar de estruturalmente bastante diferente das anteriores, na composição dos diálogos e na criação dos tipos, ela ainda é portadora da mesma atmosfera que transparece o estado emocional das principais personagens. Neste caso, a protagonista, Maria das Dores, não fala e quase não aparece em cena. Ela apenas a atravessa no momento final, quando transparece todo seu sofrimento pelo silêncio e um estremecer do corpo diante do choro do filho e da curiosidade 
das outras personagens. Na rubrica inicial, vemos a descrição do ambiente: "Uma rua tristonha... (...) No centro, ao fundo, um lampião perfila-se diante de uma árvore raquítica. A rua é vista em diagonal. Seis horas da tarde" (Idem, p. 333). Novamente aqui, o momento crepuscular é aquele que envolve os acontecimentos. E, igualmente às peças anteriores, não há uma ação propriamente dita, mas a espera pelo que possa acontecer: as personagens aglomeram-se à porta do correio enquanto esperam pelo momento em que Das Dores, uma mulher cujo caso extraconjugal veio à tona na madrugada anterior, vai embora no trem das sete. Durante a espera, apenas comentários banais e julgamentos cruéis da vida alheia.

Chamo a atenção para a composição inicial do ambiente crepuscular em que as peças se desenvolvem porque:

O crepúsculo com suas tonalidades amortecidas, em que a realidade aparente das pessoas e coisas perde a sua nitidez e contornos precisos, adquirindo um aspecto mágico ou ameaçador, simboliza perfeitamente a vida, com as criaturas humanas desgarradas num universo hostil. Ao mesmo tempo que o dramaturgo cria incessantemente imagens relacionadas à ideia de decadência e decrepitude, visualiza no palco sons e cores para traduzir estados d'alma. (FRAGA, 1992, p. 172)

Dando continuidade aos aspectos de construção do drama, é preciso atentar para esses pequenos detalhes expostos no texto, pois são eles os responsáveis pela maior parte da teatralidade do drama simbolista, uma vez que há nisso uma valorização dos detalhes, da iluminação e dos pequenos gestos:

A ambiguidade do discurso pode ser representada mediante uma relação equívoca entre as personagens e os objetos que as cercam. No teatro simbolista, nenhum objeto é decorativo; ele está ali para exteriorizar uma visão, sublinhar um efeito, desempenhar um papel na subcorrente de acontecimentos imprevisíveis. A interação de luzes e sons enfatiza as correspondências entre o físico e o espiritual, a fim de que a hora do dia, o bater de um relógio, a sugestão do vento, as variações de cor 
inundando o palco, constituam uma linguagem para cada diferente espectador (BALAKIAN, 2007, p. 100).

Com o intuito de deslocar o significado e essa teatralidade à qual me referi, esse teatro tende a esvaziar de sentido as palavras proferidas pelas personagens. O que é dito quase não tem valor, realçando dessa forma os detalhes e as minúcias da cena. Em $A$ bela tarde, encontramos essa preocupação do autor em deslocar o sentido da peça para o silêncio, tornando os diálogos vazios. Essa tendência se manifesta sobretudo na primeira parte da peça, quando a mãe e o pai conversam sobre trivialidades (o cheiro da orquídea, a passagem do cometa, os ensaios da próxima revista de Jojoca Torres), o que as impede de notar o estado de tristeza em que Nicota se encontra. $\mathrm{O}$ silêncio da filha perante o diálogo diáfano dos pais, por sua vez, é carregado de significado. Enquanto se trava, no entorno dessas três personagens, um jogo entre as palavras vazias e o silêncio, Juca é o responsável por trazer à peça um tom de blague e, em consequência, certa leveza. Seus comentários ácidos a respeito dos costumes e da sociedade, aliás, apenas servem para encobrir seu estado de tristeza.

MAMÃE: Não está bem aqui?

NiCOTA: Estou.

MAMÃE: Então?

O PRIMO JUCA: Com certeza, menos bem que o ano passado.

NiCOTA (fechando o livro): Por quê?

O PRIMO JUCA: Porque o moço Fontes já não anda por estas matas.

MAMÃE: Que tem o tenente Fontes com a vida de minha filha?

O PRIMO JUCA: Não tem nada, mãe austera. Era apenas um bom companheiro.

PAPAI: Foi ele quem me deu esta parasita. Hoje, está noivo.

MAMÃE: No Ceará

PAPAI: Era um excelente rapaz. Deve ser um excelente noivo.

O PRIMO JUCA: Todos os noivos são excelentes. ( $A$ Nicota) Hás de encontrar outro Fontes, dentro em breve.

PAPAI: Na Tijuca não faltam fontes. (E ri-se. Sem razão aliás.) (GOMES, 1983, p. 149) 
Os pais da jovem não conseguem compreender a inquietude da filha, tampouco um evidente relacionamento existente entre ela e Fontes. Apenas Juca percebeu, mas nem seus comentários abrandam a cegueira dos pais. Nota-se isso pelas interpelações da mãe e pelo comentário deslocado do pai, totalmente ausentes do universo em que Nicota se encontra. É o primo Juca quem fala: "Não vêem, não querem ver as agonias caladas daqueles que os cercam, como não quiseram ver, há pouco, a agonia silenciosa do sol.” (Idem, p. 161)

Nas rubricas encontramos as indicações mais significativas acerca do sofrimento das personagens Nicota e Juca. Nelas, a descrição do estado de espírito das personagens se ajusta à iluminação crepuscular do jardim da casa em que o ato se passa. O soluço que, em momentos específicos, elas deixam escapar é o principal representante de sua verdadeira dor:

Nicota desce ao jardim e vai lentamente ao portão, a que se encosta, olhando para fora. Ouve-se uma campainha longinqua e vêem-se umas luzes que passam rapidamente por entre as árvores. Ela murmura: "O bonde das sete"... e continua a fitar 0 borizonte. As estrelas começam a palpitar, tremulantes, e como um reflexo do céu, lá em baixo, as luzes da cidade vão aos poucos brilhando.

(...)

NiCOTA: Eu já vivi, já... eu também... eu também... (Prorrompendo em soluços e atirando-se-lhe aos braços).

(...)

O PRIMO JUCA: (...) Tratariam a tua mágoa de namorico infantil, e não me veriam sofrer sem um sorriso de escárnio, como se se pudesse sofrer e chorar por causa de... Lili Carambola! (E ouve-se na noite um risozinho irônico que se parece com um soluço.) (Idem, pp. 157161)

A respeito dessa curta peça, Roberto Gomes assim a descreveu em entrevista concedida ao jornal $O$ imparcial: "Procurei nesse acto antes suggerir do que mostrar. (...) Através dessas duas pequenas dores particulares, procurei fazer sentir um pouco a outra dor, a grande dor da solidão de que soffrem todos os homens" (apud COSTA, 1978, p. 81). 
Já em $O$ jardim silencioso e $A$ casa fechada, as palavras detêm funções diferenciadas. Enquanto na primeira elas têm o poder da revelação, na segunda são usadas para camuflar intenções e mágoas recalcadas. No caso de $O$ jardim silencioso, os símbolos são explícitos e indicam que a felicidade da casa é apenas aparente, como o próprio título sugere, já que o silêncio presume a encoberta de múltiplos sentimentos. Também bastante significativo, no texto, o silêncio inicial da filha do casal, Helena, que apenas responde monossilabicamente às perguntas do pai e da tia. Será ela a responsável por trazer à luz todas as dores vividas naquela casa. A jovem tem função semelhante à do Primo Juca na peça anterior: ver o que ninguém aceita enxergar na aparente calma e tranquilidade:

MARIANA: Essa vida que levam não é boa para a alma. HELENA: Cada qual vive como entende, tia Mariana, como pode.

MARIANA: Como pode não quer dizer como deve.

HelenA: Esta casa é um pouco triste. Papai e mamãe procuram, às vezes, distrair-se. Recebem alguns amigos. Não há mal nisso.

MARIANA: Essas vãs distrações do mundo não dão repouso ao espírito. Poderiam ficar aqui, como você, sem todos esses chás. Não compreendo que você não seja religiosa! Olhe como está a casa tranquila. E o jardim? Que silêncio! Que paz!

HelenA: Ah! Se formos pensar assim! Aceitemos a vida como o céu nô-la manda e agradeçamos o pão de cada dia... (Idem, p. 192)

A fala resignada de Helena aponta para o perfil das protagonistas dos dramas simbolistas, pois nada resta a fazer senão esperar pelo que o destino lhes reserva. Esse espírito decadentista, de descrédito no porvir, aparece em outros momentos: "Se alguma coisa sucedeu, minha tia, já é tarde" (Idem, p. 193). Sobretudo, a resignação aparece nas palavras proferidas ao pai sobre a situação em que se encontravam, de dores escondidas sob uma aparente felicidade. Diante do sofrimento da mãe e da indiferença do pai, nada restava senão a impossibilidade de ação: 
PEDRO: Então, por que te calaste?

HELENA: Que palavras dizer?

PEDRO: Por que não procuraste impedir?

HELENA: Que gestos fazer? Entre os dois estava eu como uma estátua algemada, prisioneira do silêncio. Eu bem previra o dia de hoje, mas nada podia tentar para evitá-lo. (Idem, p. 200)

As palavras, neste momento, são reveladoras. Elas devem suprir a falta de um quotidiano silencioso, revelar as dores para que possam aceitar passivamente uma vida em comum, mesmo que ainda carreguem os fantasmas do passado. O pai, com orgulho ferido, a princípio não aceita a traição da esposa, mas se resigna com o sofrimento silencioso da filha:

HELENA: Antes a dor em comum que a solidão sinistra em que vivíamos, mergulhados na noite espessa da mentira! Já podemos gritar as dores que sufocavam em nós. Já vemos a luz do céu.

PEDRO: A luz!

HeLENA: Não é a luz gloriosa do sol. É uma pobre luz cinzenta e triste. Mas é preferível às trevas em que agonizávamos. Ah! Pai! Sofri, sofri tanto, sentia-me por vezes tão desanimada que desejava morrer... Ah! Sim... Morrer! Agora podemos chorar juntos... já é uma felicidade. (Idem, p. 202)

O jardim silencioso se aproxima muito da estética simbolista, seja pelo tom amargo e pessimista em relação à vida, seja pela temática da dor sofrida em silêncio, embora tudo isso esteja expresso no diálogo de Helena com seu pai.

O drama do silêncio e do sofrimento interior paradoxalmente é expresso pela palavra. Os fatos chegam ao leitor através da narração. A própria protagonista é um ser de palavras pois não tem corpo nem voz. (COSTA, 1983, p. 38)

Esta narração proporciona ao drama o mesmo efeito de oposição sujeito-objeto visível nos dramas de Maeterlinck, quando o homem - e seu sofrimento - torna-se objeto do drama, não mais seu sujeito de ação. O sofrimento realmente é dito, dando importância incomum às palavras; mas esse processo de 
distanciamento verbal da dor evidencia um efeito epicizante, dando destaque ao homem enquanto objeto e não enquanto sujeito. É o que se pode notar também em $A$ casa fechada, em que todas as personagens comentam a situação da protagonista Maria das Dores. Aqui, as palavras também têm sua força narrativa, acrescentando o fato de apontarem para o caráter mesquinho e fofoqueiro da pequena cidade interiorana, representada pelos tipos que ficam à porta do Correio. Os diálogos são enxutos, subliminares e denotam o perfil e interesse de cada um.

Aos poucos, as personagens se aglomeram à porta do Correio a fim de observar a casa fechada, silenciosa e às escuras. Nessa espera pela partida de Maria das Dores, há um jogo entre o dito e não dito, entre a palavra e o silêncio, estabelecido entre o espaço do Correio e o da casa. Enquanto no Correio a palavra é sentenciosa e cruel, na casa o silêncio é doloroso. Também é essa distinção que estabelece a divisão estética entre o sujeito e objeto do drama, anulando a ação e enfatizando a situação representada, em procedimento muito próximo àquele usado por Maeterlinck em Intérieur. Todos, curiosos, encontram desculpas para permanecerem naquele ambiente até que a protagonista passe em direção à estação de trem. Nesse estado de espera, eles narram os fatos e o comentam, julgando a mulher à luz de uma moral interiorana e preconceituosa.

JOAQUim AgUACEIRO: Agora vai p'ra casa?

O PESCADOR: Vou, sim, patrão. (Pausa. Ele não se move) Vou, sim... (Permanece imóvel. Afinal, dá um passo e pára. Mostrando a casa ao longe, com a cabeça) Ainda estão lá dentro?

DONA SINFONIA: Estão sim. Há mais de uma hora. JOAQUim AguACEIRO: Ele é capaz de descobrir a coisa.

O PESCADOR: Ah! Com o Dr. Aprígio ninguém escapa. Moleque feio tem de entrar nela.

DONA SINFONIA: Não se ouve nada.

O PESCADOR: Nada. Está tudo fechado. Parece que estão a velar um defunto.

DONA SINFONIA: Desde a manhã, ninguém saiu. (GOMES, 1983, p. 334) 
Está lançado o mistério e a situação está elaborada já nesta primeira cena, o que só se intensifica à medida que mais personagens se aproximam do grupo. O boticário vai comprar selos, D. Ritoca vai ver se chegaram cartas, o pescador vai postar uma carta para o filho, todos se aproximam com um objetivo, expresso pelas rubricas, pelas intenções e subliminarmente pelas palavras proferidas:

(Dona Eudóxia aparece à porta do Correio. Joaquim Aguaceiro, com indiferença afetada, vai se aproximando da casa fechada e passa lentamente rente às janelas.)

(...)

DONA EUDÓXIA: Deseja alguma coisa?

O BOTICÁRIO: Preciso de uns selos. Mas não há pressa... não há pressa...

(...)

DONA SINFONIA: Ouviu alguma coisa?

JOAQUim AguACEIRO: Nada. Está tudo calado. (Idem, p. 335)

Maria das Dores é o objeto dos comentários, mas só aparece em cena no final e não diz palavra. Assim como Noêmia, da peça anterior, aqui ela é representada como um vulto (seriam elas apenas fantasmas do sofrimento do homem?). Neste momento, em contraste com os diálogos enxutos e, em certo sentido, ausentes de força significativa, a dor da personagem é expressa pelos soluços, pelo silêncio e por um leve estremecer do corpo. A peça procura sintetizar alguns dos principais aspectos simbolistas, sem deixar a outra face da dramaturgia de Roberto Gomes, de olhar sarcasticamente para a sociedade e para as leis que a regem. A casa fechada, símbolo do sofrimento silencioso, finalmente se abre diante do olhar curioso das personagens e do público:

(Abre-se de novo a porta, e, destacando-se, no fundo luminoso da sala, aparece no limiar o vulto de Maria das Dores. Um grande xale preto cobre-lhe a cabeça e cai até os joelhos. Na mão, uma pequena trouxa. Ela começa a caminhar, rígida, de rosto fechado, sem olhar para ninguém. Ouve-se um sussurro no grupo. Mas alguém faz. "Pst" e o silêncio torna-se geral. Todas as personagens estão na penumbra. Só o velho mendigo iluminado 
pela luz do lampião. Quando Maria das Dores passa por ele, ele ergue-se e tira o chapéu. Então, no meio do silêncio mortal, ouvese um soluco abafado e desesperado. É o filho que está chorando, encostado no muro. Ela tem um longo estremecer do corpo todo. Atrasa insensivelmente o passo um segundo, mas continua a caminhar sem um gesto e sem se voltar. Todas a acompanham com os olhos. Ouve-se novamente o silvo da locomotiva.) (Idem, p. 347)

Essas três peças de Roberto Gomes se aproximam umas das outras não apenas pela temática, mas também pela composição estética - uma tentativa de aproximação do simbolismo com o uso de seus mais conhecidos recursos - e pela própria constituição dramática: apenas um ato, diálogos enxutos e um evidente jogo de cena entre o interior e o exterior: o interior da casa e o jardim ( $A$ bela tarde), a sala e o jardim ao fundo $(O$ jardim silencioso), a casa fechada e a cidadezinha (A casa fechada). Essa própria construção as aproxima do drama maeterlinckiano, sobretudo com Intérieur, ajustando ainda mais a dramaturgia do autor brasileiro com o modelo estético.

\section{REPENSANDO O INÍCIO DO SÉCULO XX: MODERNIDADE} DRAMÁTICA?

A partir de uma perspectiva de renovação dramática, o teatro simbolista teve fundamental importância para a modernização teatral, na medida em que a partir da quebra dos elementos tradicionais do drama foi necessário ajustar também os elementos da cena. A composição dramática também se altera significativamente, readequando esteticamente a representação do homem e trazendo nítidas alterações na linguagem, na quebra da estrutura tradicional do drama e no enfoque da teatralidade.

A linguagem se autonomiza [em Maeterlinck], e desaparece seu vínculo essencialmente dramático com a situação: ela já não é mais a expressão de um indivíduo que espera a resposta, apenas reproduz a disposição de ânimo que domina todas as almas. Sua divisão em várias "falas" não corresponde a uma conversação, como no drama genuíno, mas espelha 
unicamente a oscilação nervosa da ignorância. (SZONDI, 2001, p. 73)

Em que medida a dramaturgia de Roberto Gomes auxiliou na composição do drama moderno brasileiro? Pode-se pensar em modernização no teatro brasileiro a partir de sua proposta dramática? Talvez o que essa tentativa suscite seja a reflexão em torno das propostas e a ausência de uma continuidade estética na história do teatro no Brasil.

A década de 10 do século XX, no Brasil, é marcada pela presença constante de comédias ligeiras, do teatro musicado, do teatro de revista e pelas apresentações de companhias estrangeiras, responsáveis pela fatia "séria" do teatro. Em contraponto a esse contexto imediato, Roberto Gomes se posicionou contra o teatro para rir e procurou desenvolver dramas esteticamente aprimorados, influenciados por um movimento europeu, no intuito de propor novos formatos dramáticos para a cena nacional. O teatro de Roberto Gomes, com sua inação no palco, evidencia um momento de crise dramatúrgica por dois motivos principais: por um lado, o ostracismo a que foi relegado por uma incompreensão de seus temas e sua estética; por outro, a incompreensão do dramaturgo em relação àquele momento específico da história do teatro nacional e das condições sociais e contextuais em que se encontrava. Sua produção, em certo sentido audaciosa, é estranha ao meio em que está inserida, uma ideia fora do lugar, e só torna ainda mais evidente o momento delicado e complexo pelo qual o teatro brasileiro passou nesse início de século.

Se pensarmos na composição estética dos dramas, Roberto Gomes procurou no simbolismo formatos interessantes para a representação do conflito individual do homem, mas teve pouco impacto sobre a história do teatro brasileiro. Suas protagonistas se tornam objeto de comentários - há uma oposição sujeito-objeto -, o que ocasiona o rompimento da estrutura dramática tradicional, com a sugestão de novos 
formatos cênicos e a centralização da teatralidade em outros aspectos além do diálogo (como nos gestos, na iluminação). Foram tentativas inócuas, pois não encontraram um encenador que as levasse à cena de forma efetiva e produzissem ecos na dramaturgia nacional que veio a seguir.

\section{BIBLIOGRAFIA CITADA:}

BALAKIAN, Anna. O simbolismo. Tradução de José Bonifácio. São Paulo, Perspectiva, 2007.

COSTA, Marta Morais. A obra dramática de Roberto Gomes: temas e configuração. 1978. Dissertação (Mestrado em Literatura Brasileira), São Paulo, FFLCH/USP.

. Em cena, pequenas sombras frágeis. In: GOMES, Roberto. Teatro de Roberto Gomes. Rio de Janeiro, INACEN, 1983.

FRAGA, Eudinyr. O simbolismo no teatro brasileiro. São Paulo, Art \& Tec, 1992.

GOMES, Roberto. Teatro de Roberto Gomes. Rio de Janeiro, INACEN, 1983.

MAETERLINCK, Maurice. Intérieur. In: Théatre II. $13^{\text {ème }}$ edition. Bruxelles; Paris: P. Lacomblez/ Per Lamm, 1904.

O tesouro dos humildes. Tradução de Maria José Sette Ribas.

São Paulo, O pensamento, 1945.

MOLER, Lara Bisoli. Da palavra ao silêncio: o teatro simbolista de Maurice Maeterlinck. 2006. Tese (Doutorado em Letras), São Paulo, FFLCH/USP.

PICON-VALLIN, Béatrice. A arte do teatro: entre tradição e vanguarda. Organização de Fátima Saadi. Rio de Janeiro, Teatro do Pequeno Gesto; Letra e Imagem, 2006.

SZONDI, Peter. Teoria do drama moderno [1880-1950]. Tradução de Luiz Sérgio Rêpa. São Paulo, Cosac \& Naify, 2001.

Résumé: Cet article a pour objectif l'analyse des influences de la dramaturgie du théâtre symboliste dans l'oeuvre de Roberto Gomes (1882-1922). Il s'agit ici d'évaluer dans quelle mesure cette tendance a contribué à donner son impulsion au théâtre moderne brésilien. Chez Roberto Gomes, principalement sous l'influence de Maurice Maeterlinck, l'axe central a été davantage le silence imposé sur la scène que le dialogue en tant qu'élément suprême de communication dramatique. Ces changements dans l'esthétique du drame aidèrent-ils le théâtre national dans la modernisation tant souhaitée?

Mots-clefs : théâtre symboliste; Roberto Gomes ; drame moderne. 